\title{
Limitations in Simplified Approach in Assessing Performance of Façade under Blast Pressures
}

\author{
Lumantarna, R. ${ }^{1}$, Ngo, T. ${ }^{1}$ and Mendis, P. ${ }^{1}$
}

\begin{abstract}
The main function of building facades, which often consists of glazing windows, is to provide protection to the occupants and contents of the building from external hazards. In a blast event, the facade component of a building may become the weakest link of the structure, whereby its breach may lead to blast pressure ingress and hazardous projectiles into a structure. This paper reports part of a study to establish the performance of glass windows under blast pressures. Two modelling techniques were used to simulate the response of a façade panel. They are the Single Degree of Freedom (SDOF) modelling technique and the Finite Element (FE) modelling technique. Although the SDOF approach can be used with a reasonable degree of accuracy, the limitations of its basic assumption lead to loss of details in the idealisation process. This paper presents an attempt to establish performance indices of a façade panel, and to identify the discrepancies between simplified approach and the detailed numerical modelling approach analysis.
\end{abstract}

Keywords: Blast pressures, negative phase, explosion, P-I curve, façade.

\section{Introduction}

Glazing elements often cover the majority of the facade of modern structures. The main function of the facade is to protect building occupants from external elements that may induce personnel discomfort, injuries and fatalities. At the extreme level, these external hazards may vary, from natural hazards, such as earthquakes, cyclones, flash floods, tsunamis or heat waves; to technical hazards, such as explosions, impacts or fires. This paper presents part of a study to quantify the performance of the glazing façade panel under blast pressures from explosive technical hazard.

Glazing element, when untreated, will break into knife-shaped shards, which when propelled at high velocity would turn into a major source of injuries in the case of a blast event [1]. Moreover, the failure of the glazing panel will lead to blast pressure ingress into the structure that may cause additional damage to the building, and blast pressure related injuries. This highlights the importance of understanding the vulnerabilities of the glazing façade element when subjected to blast pressures.

The performance assessment of the glazing panels that are in day-to-day production relies on an empirical approach, to proof-test the performance standard of the glazing panels using an impact shotbag test [2] or destructive airblast loading tests [3].

\footnotetext{
${ }^{1}$ Department of Infrastructure Engineering, The University of Melbourne, Melbourne, AUSTRALIA

Email: lur@unimelb.edu.au
}

Neither of these contemporary control measures involves an understanding of the physical phenomena governing the behaviour of facade systems when subjected to blast pressures. Furthermore, the aforementioned destructive tests are costly to set up, hence the need to establish the performance of glazing panels through an analytical method.

Fragility curves [4] or pressure impulse (P-I) curves [5], which are developed for a particular glazing panel, have been used as a vulnerability assessment tool. Although this is a very comprehensive tool in modelling the probability of failure of a particular window glass panel when subjected to blast pressures, the fragility curve only represents one particular charge weight. Extensive analysis of a variation of charge weights would need to be carried out to establish the performance characteristic of a glazing panel. On the other hand, the P-I curve provides end-users with one characteristic curve for a particular glazing panel, albeit without the comprehensive probability distribution of glazing panel failure. In this exercise, the P-I approach will be used.

In the past, dynamic analysis of glazing units has focused on the use of a Single Degree of Freedom (SDOF) idealisation of the glazing panel, while P-I curves based on the aforementioned SDOF principles have been used as performance indicators. However, there are some limitations in the SDOF model since it cannot capture the change in deflected shape and failure modes due to the inertia effect of the glazing panel. This is a general issue that has been raised in several studies $[6,7]$.

Alternatively, a detailed Finite Element (FE) approach can be used to establish the performance 
indices of the façade component. Detailed FE analyses are often expensive in terms of computational hours and resources requirements, which is not ideal for engineers who often needs to carry out design tasks with limited resources. The trade-off between loss of details and computational cost are deemed acceptable as long as conservative estimates are obtained from the analysis. This highlights the importance to establish clear understandings on engineering parameters which influences the discrepancies between detailed analysis and simplified approach.

The exercise presented in this paper is an attempt to establish the performance characteristics of glazing façade panels in the form of P-I curves, and establish the loss of details induced in the common simplification process adopted by engineers. This work is part of a research project which investigates the behaviour and performance of glazing façade when subjected to blast pressures. The analytical framework required to develop the aforementioned P-I curve will be briefly discussed. Then, the P-I curves of typical glazing panels will be developed based on a FE model and the simplified approach. Finally, the loss of details observed in the simplified approach as compared to the detailed FE model will be discussed.

\section{Background}

There are two major factors that differentiate blast pressures from other extreme loads. They are the load duration and the magnitude of the applied pressures. Depending on the distance between blast source and target, the load duration in a blast pressure may vary between a few milliseconds and hundreds of milliseconds, which is typically several orders of magnitude lower than typical wind, earthquake or other conventional load. On the other hand, the magnitude of the applied pressure may rise to several orders of magnitude greater than other conventional loads.

Blasts from different sources, weights, and distances have one typical pressure time history profile, which can be divided into two phases. The first phase is the positive phase, which is a result of rapid expansion of the explosive gas. Due to the rapid expansion of the core of the explosive, a shell of pressurised air is formed on the outer most layer of the expanding gas, which is defined as the blast wave-front [8]. This phase is characterized by a suddenly applied high overpressure and relatively short duration. The second phase is the negative phase, which is created by the momentum of the rapidly expanding gas of the positive phase. The peak magnitude of the negative phase is significantly lower than to the peak overpressure magnitude, while the duration is significantly longer. The typical pressure time his- tory is shown in Figure 1, which is a form of the modified Friedlander exponential equation [8].

$P(t)=P_{s}\left[1-\frac{t}{T_{d}}\right] e^{\left(\frac{\beta t}{T_{d}}\right)}$

Where, $\mathrm{P}_{\mathrm{s}}=$ peak overpressure, $\mathrm{T}_{\mathrm{d}}=$ positive phase duration, $\mathrm{t}=$ time and $\mathrm{B}=$ waveform parameter.

The typical pressure time history of a blast event is characterised by wavefront parameters, such as the arrival time, peak pressure, peak impulse, blast duration and the waveform parameter of the pressure wave. The magnitude of these wavefront parameters are directly influenced by the mass of explosive source, the stand-off distance between explosive source to the target and the geometrical reflection of blast from the surface of the target.

In order to take into account the geometrical reflection of blast pressures on the target, the term angle of incidence is used. An unobstructed pressure wave is also known as incident pressure. A fully reflected blast pressure is a result of the interaction between blast incident pressure wave and a solid structure at $0^{\circ}$, whereas a side-on pressure is a result of interaction between blast incident pressure and target pressure at $90^{\circ}$. The varying angle of incidence results in different magnitude of peak pressure parameter. Detailed Computational Fluid Dynamics (CFD) would need to be carried out in order to take into account other geometric parameters such as multiple reflections off complex surfaces and pressure propagation in confined spaces.

The prediction of blast wavefront parameters can be carried out through two different techniques. They are the semi empirical approach in CONWEP [9] and numerical approach through Computational Fluid Dynamics (CFD) analysis [10].

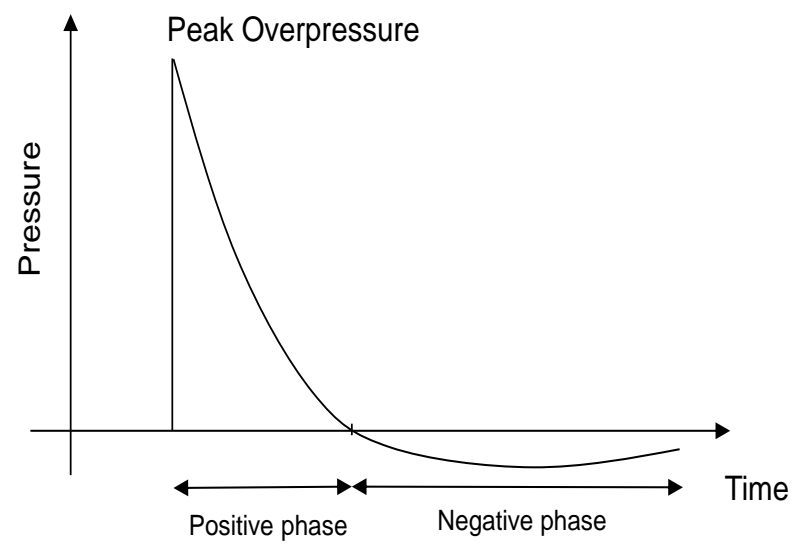

Figure 1. Typical Blast Pressure Time History 


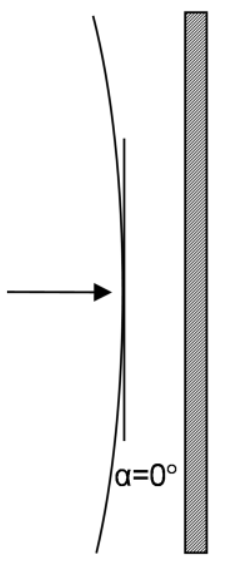

Incident wave

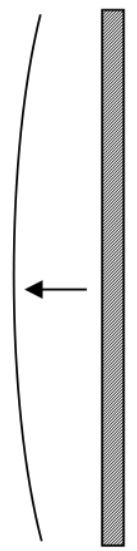

Reflected wave

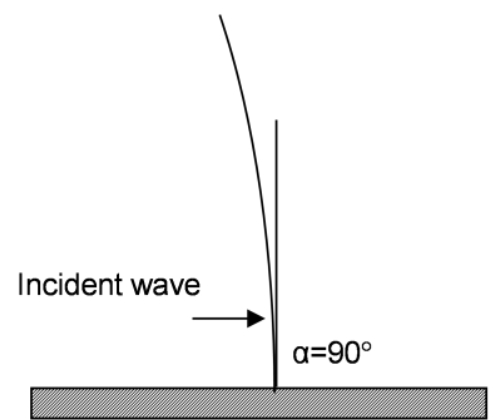

Figure 2. $0^{\circ}$ Angle of Incidence and $90^{\circ}$ Angle of Incidence

Typical Blast Pressure History

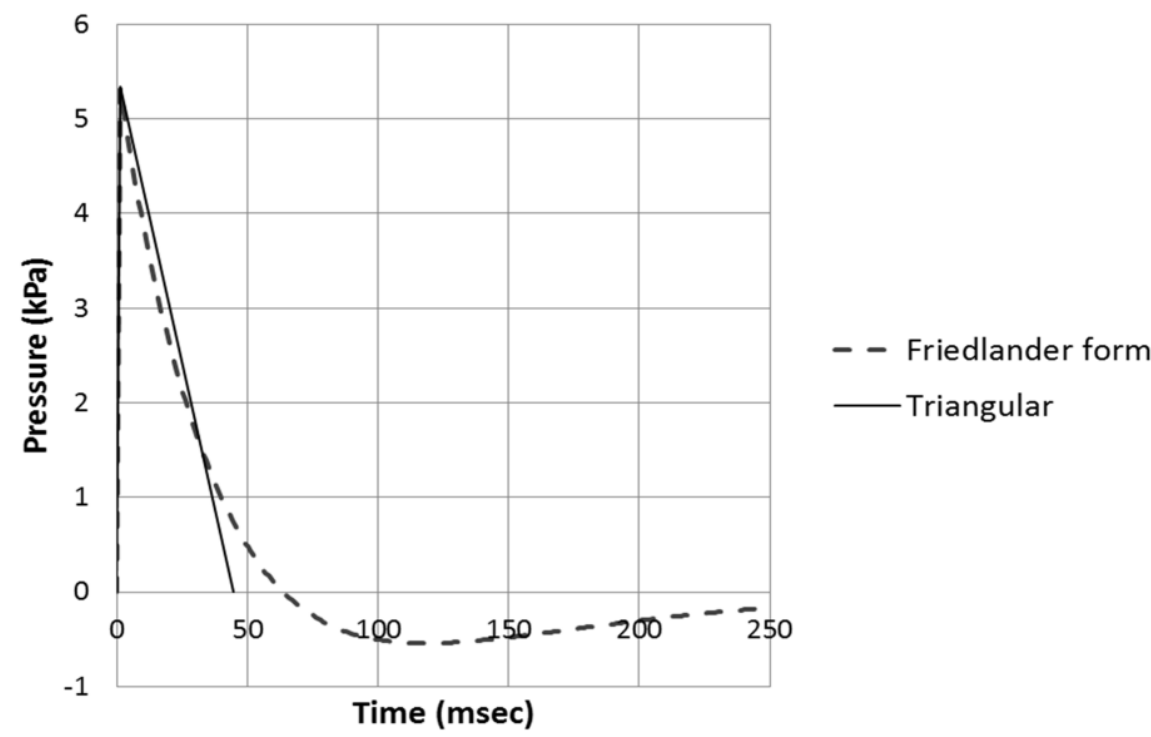

Figure 3. Blast Pressure Simplification to Triangular Shaped pressure Time History

The CONWEP approach is based on the Kingery and Bulmash model [11], which had been adopted in the Unified Facilities Criteria (UFC) design guidelines of structures to resist the effects of accidental explosion [12], is widely accepted due to the extensive range of test database used in its derivation. The CFD approach whilst provides a detailed and accurate prediction of the blast pressures [13], tends to require a significant amount of resources in terms of computational cost. Hence, in engineering practices which often requires quick estimates with reasonnable accuracy, the Kingery and Bulmash model is generally preferred.

In UFC guidelines, blast resistance analysis of structural or shielding component used the principles of
SDOF approach, whereby structural component is idealised into a spring-lumped mass system, and the blast pressure is idealised into a point load acting on the idealised system. In the guidelines, the blast pressure estimate can be reduced to a triangular shaped load time history by retaining two critical blast characteristics of peak reflected pressure and peak reflected impulse (see Figure 3). Although it is acknowledged in the guidelines that component failure may occur in the rebound (outward motion) response phase, the negative phase influence in the response of the component is not clearly established. Furthermore, previous investigation indicated that the response estimates obtained from the simplified triangular pressure history approach may result in an un-conservative design [14]. 


\section{P-I Curve}

An iso-damage (pressure impulse) curve is a performance curve that represents a certain damaged state of an element. Traditionally, P-I curves were developed from damage assessment after an event or from experimental results. However, an empirical approach requires extensive testing, which requires a significant amount of resources. Analytical SDOF approach to develop the P-I curves is well established $[8,15]$. In more recent studies, Shi et al. have developed P-I curves through a combined numerical and analytical method for reinforced concrete columns [16].

Adopting the SDOF approach, a structural component can be idealised into an effective lumped mass and spring system, whereas the blast pressure can be idealised into an applied point load on the effective spring-mass system. The damage criteria of the component can be identified based on the displacement demand required to achieve the damage level. For every component with unique mass and stiffness, the critical displacement can be achieved when the component is subjected to a series of pressure and impulse combinations. The P-I curve is established by plotting the full spectrum of the critical pressure and impulse combinations.

Based on the maximum allowable displacement, the impulsive and quasi-static asymptote on the P-I curves can be quickly established by applying simple energy conservation principles. In general, when subjected to a varying pressure and impulse combination, the response of a structure is governed by the natural period $\left(\mathrm{T}_{\mathrm{n}}\right)$ of the structure and blast load duration $\left(\mathrm{T}_{\mathrm{d}}\right)$. Hence, there are three possible scenarios that could occur in the blast event:

- $\mathrm{T}_{\mathrm{d}}>>\mathrm{T}_{\mathrm{n}}$ (Quasi-static response)

- $\mathrm{T}_{\mathrm{d}}<<\mathrm{T}_{\mathrm{n}}$ (Impulsive response)

- $\mathrm{T}_{\mathrm{d}}$ within range of $\mathrm{T}_{\mathrm{n}}$ (Dynamic response)

The quasi-static condition occurs when the centre of explosion is located at a significant the stand-off distance to the target structure. Typically, this loading condition exhibits relatively low peak overpressure, but very high specific impulse. Under a quasi-static loading condition $\left(\mathrm{T}_{\mathrm{d}}>>\mathrm{T}\right)$, the blast load can be idealised as a load which dissipates very slowly over time. In this type of response, the component would be able to respond to the excitation load before the blast overpressure decays to ambient condition. Hence, the peak pressure of the blast governs this loading condition. Assuming that energy loss in the structure is negligible, the work done on the system, as it is displaced, is converted fully into the internal strain energy.
Equation (1) shows the energy conservation equation where $\mathrm{F}=$ the peak blast load, $\mathrm{x}_{\max }=$ maximum displacement criteria and $\mathrm{K}_{\mathrm{eff}}=$ Effective stiffness of the system.

$\mathrm{Fx}_{\max }=\frac{1}{2} \mathrm{~K}_{\mathrm{eff}} \mathrm{x}_{\max }^{2}$

On the other hand, impulsive loading condition occurs when the centre of explosion is located at a close proximity to the target structure. Under an impulsive loading condition $\left(\mathrm{T}_{\mathrm{d}}<<\mathrm{T}_{\mathrm{n}}\right)$, the blast load can be idealised as a rapidly dissipating pressure. The peak overpressure in this loading condition is significantly higher than the quasi-static loading condition, whereas the specific impulse is relatively lower than the quasi- static loading condition. In this type of response, the blast pressure would decay to ambient condition before the component reached its peak response. Assuming that energy loss in the system is negligible, the kinetic energy applied on the structure is converted fully into the internal strain energy. Equation (2) shows the energy conservation equation where $\mathrm{I}=$ peak reflected impulse, $\mathrm{x}_{\max }=$ maximum displacement criteria and $\mathrm{M}_{\mathrm{eff}}=$ Effective mass of the system

$$
\frac{\mathrm{I}^{2}}{2 \mathrm{M}_{\mathrm{eff}}}=\frac{1}{2} \mathrm{~K}_{\mathrm{eff}} \mathrm{x}_{\text {max }}^{2}
$$

The generic non-dimensional P-I curve is as shown in Figure 4.

The concept of iso-damage curves has a wide range of applications as damage assessment tools. Once a performance criterion of a component has been defined as a P-I curve, the damage/non-damage state of a component can be quickly established by checking whether the component is subjected to a pressure-impulse combination which exceeds the limit defined in the P-I curve.

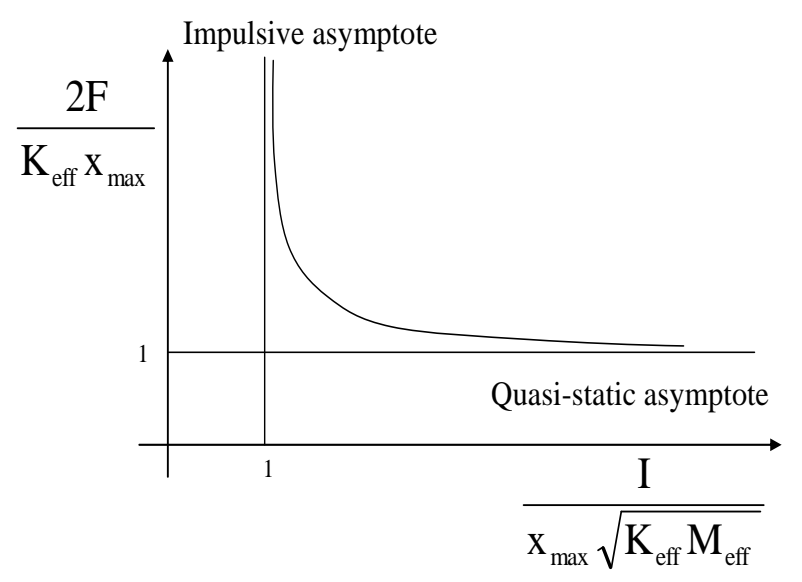

Figure 4. Generic Non-dimensional P-I Curve [8] 


\section{Development of Performance Indices}

Based on the UFC3-340-02, window glass performance subjected to blast pressure can be analysed using SDOF approach [12]. The recommended pressure application is planar blast pressure, which results in uniformly distributed pressure over the surface of the panel. The pressure may be simplified into the triangular pulse shape as described in previous section. Although it was acknowledged that the failure in rebound movement may occur, there were no indications on the direct influence of the negative face of the blast pressure on the performance of the glazing component. Material damping was also not taken into account in the analysis to achieve conservative estimates. The main objecttive of this exercise is to clearly decouple the effect of the simplification measures on the P-I spectrum of a facade component.

In order to decouple the effect of the simplified approach, two modelling techniques were used in the analysis; the simplified SDOF approach and the FE analysis approach. The simplified SDOF approach was carried out with triangular pulse shape without negative phase. The detailed $\mathrm{FE}$ analysis was carried out in two stages. The first stage was to establish the loss of details due to SDOF idealisation, whereby the pressures applied to the FE model were limited to the positive phase. In the second stage, the model was subjected to positive phase followed by negative phase in order to decouple the effect of the negative phase in the analysis. The negative phase in the model was established based on the modified Friedlander equation as adopted in CONWEP [9].

The detailed FE analysis could take into account details such as framing brackets, mullions, transoms and lamination, into the analysis. However, there are possibilities that discrepancies between the $\mathrm{FE}$ model and the SDOF model may be introduced in the idealisation process of a complex system. In order to eliminate these discrepancies, the model was limited to simple system of a laminated glass panel with simple support, which allows for a straight forward idealisation. The glass panel is a $12 \mathrm{~mm}$ thick annealed glass panel with surface area of $1200 \mathrm{~mm}$ by $1600 \mathrm{~mm}$, which is a typical dimension for a punch window or strip window facade system.

A pressure-impulse curve can be obtained by plotting the blast pressure and impulse combination required to induce a certain level of damage criteria to an element. Figure 4 shows the calculation procedure used in the analysis. Both SDOF model and explicit FE code LS-DYNA [16] were used to assess the response of the glass panel.
In the analysis, blast pressure and impulse were variable parameters that were randomised at each simulation. The results obtained from the FE model were assessed against a particular failure criterion.

The pressure and impulse combinations needed to induce the condition were recorded as P-I points and grouped into the 'fail' batch. If the P-I combinations were not adequate to induce the 'fail' condition, the analysis would be repeated with a different set of P-I values. This process was repeated numerous times to define the full spectrum of P-I curves.

The failure criteria of glass panel in the analysis can be defined in terms of principal stress level at the associated probability of failure. In this analysis, $50 \%$ probability of failure based on the distribution shown in Table 1 was used. The cumulative probability of failure is shown in Figure 6 .

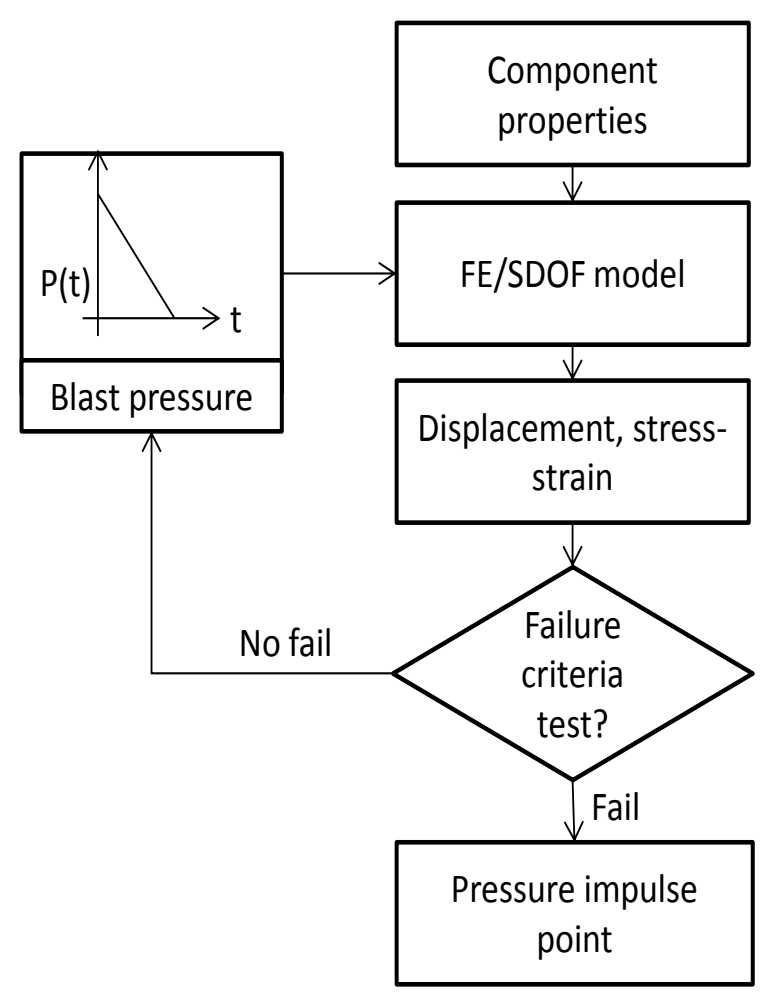

Figure 5. Analytical Procedure

Table 1. Failure Stress of Different Glass

\begin{tabular}{lll}
\hline Type of Glass & Mean (MPa) & $\begin{array}{l}\text { Standard } \\
\text { Deviation }(\mathrm{MPa})\end{array}$ \\
\hline Annealed & 84.8 & 23.7 \\
Heat Strengthened & 97.7 & 14.7 \\
Toughened & 159.6 & 16.0 \\
Chemically Strengthened & 102.8 & 15.4 \\
\hline
\end{tabular}

Source: Crawford [18] 


\section{Annealed Glass Strength Distribution}

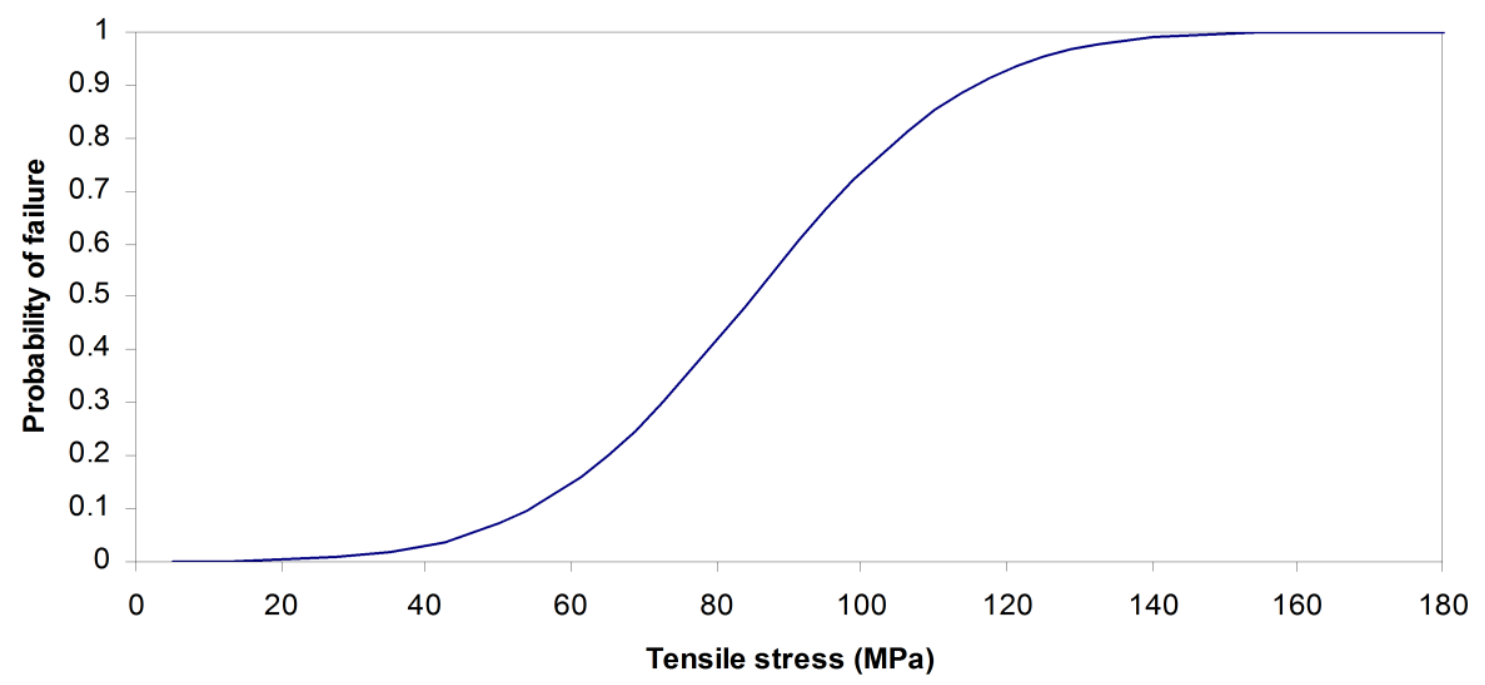

Figure 6. Probability of Failure of Annealed Glass

\section{Results and Discussion}

The pressure and impulse curve obtained from both SDOF and FE analysis are presented in Figure 7. As expected, clear quasi-static and impulse driven impulsive asymptotes can be observed on both SDOF model and FE analysis results. There is a good correlation between the SDOF model and the FE model quasi-static asymptotes in the quasi-static region, which indicates that both SDOF and FE model exhibits similar level of resistance. However, the results indicate that the SDOF model appears to exhibit greater impulse resistance than the $\mathrm{FE}$ model.

Examples of displacement time histories of panels subjected to quasi-static loading conditions and impulsive loading conditions are shown in Figure 8 and Figure 9 respectively. It can be observed in Figure 8 that despite small discepancies due to geometrical nonlinearity, which was not captured in the SDOF model, the displacement time histories of panels under quasi-staitc loading conditions are in general agreement. On the other hand, notable discrepancies can be observed in Figure 9 due to the higher mode of vibration captured in the FE analysis approach. The higher mode of vibration leads to stress concentrations along the surface of the panel, which results in lower peak displacement at failure stress criteria. The higher mode effect generally occurs when the ratio of blast duration and natural period of target structure $\left(\mathrm{T}_{\mathrm{d}} / \mathrm{T}_{\mathrm{n}}\right)$ was less than 0.25 .
The higher mode of vibration was engaged when the blast pressure dissipated in a very short time, with a similar duration to the natural period of the higher mode of vibration $\left(0.5<\mathrm{T}_{d} / \mathrm{T}_{\text {nhigh }}<1.5\right)$.

The effects of higher mode of vibration are predictably not captured in the SDOF approach due to its single lumped mass limitation. The aforementioned differences in the impulsive region of response are reflected in the P-I curve developed for the component. The discrepancies observed in the impulsive load region can be attributed to the tendency of the panel to exhibit higher mode of vibration due to the short duration of the blast pressures.

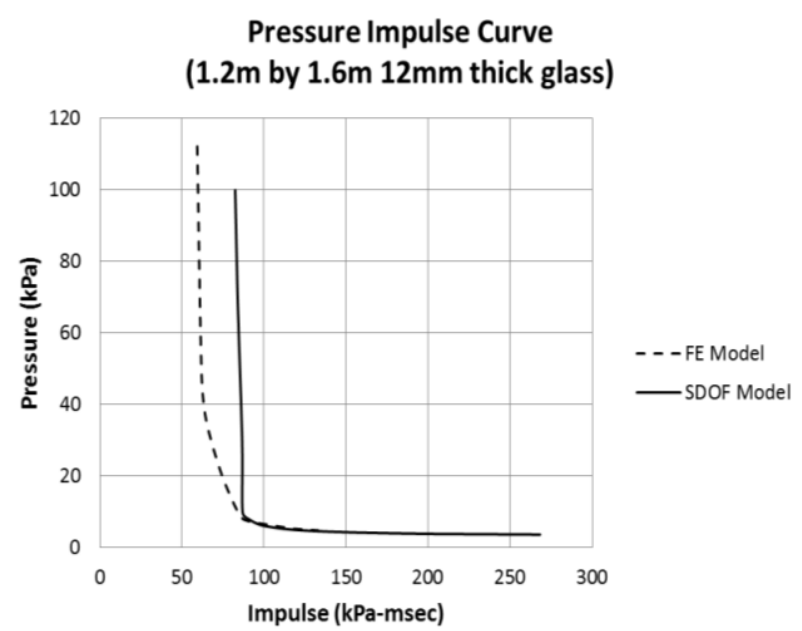

Figure 7. P-I Curve Comparison between SDOF Model and FE Model 


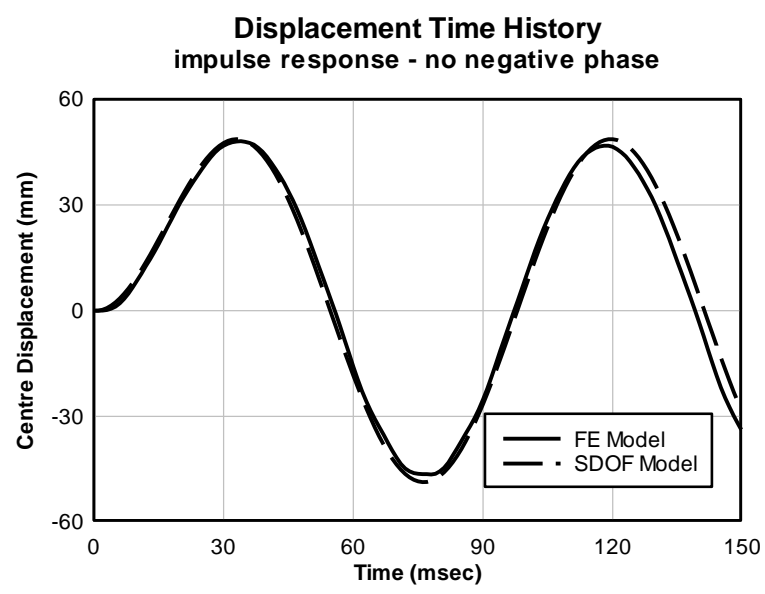

Figure 8. Comparison between FE Model and SDOF Model Subjected to Quasi-static Loading Conditions without Negative Phase

Displacement Time History impulsive response - no negative phase

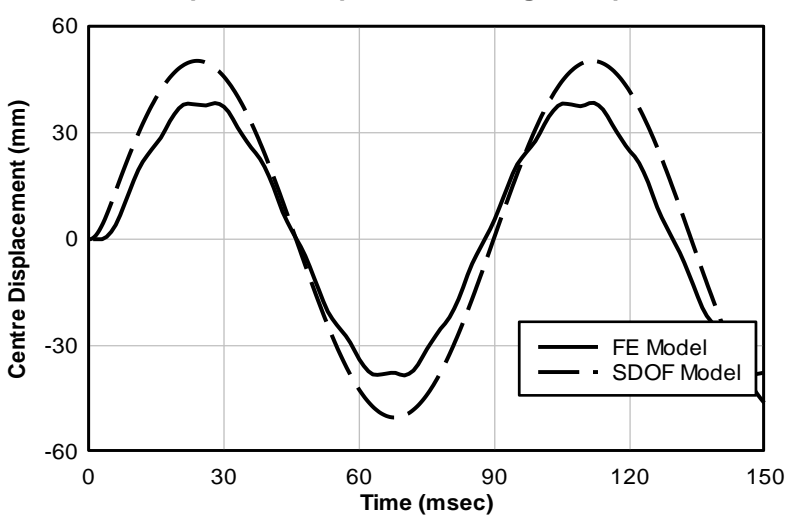

Figure 9. Comparison between FE Model and SDOF Model Subjected to Impulsive Loading Conditions without Negative Phase

Figure 10, Figure 11 and Figure 12 highlight the influence of negative phase in the response of panels under quasi-static and impulsive loading conditions respectively. The results indicate that the influence of the negative phase inclusion in the analysis is minimal in the quasi-static region, whereby the displacement time history from both analyses appears to be in general agreement. However, the influence of the negative phase becomes more pronounced in the dynamic and impulsive regions of the analysis. Figure 11 shows that the negative phase seems to reduce the peak displacement of the panel in the impulsive region. On the other hand, Figure 12 shows that in under dynamic loading condition, the negative phase enhances the outward displacement of the panel, which may lead to failure during panel rebound. In this exercise, the reduction of peak pressure occurs when $T_{d} / T_{n}$ is less than 0.1. The rebound failure typically occurs when $T_{d} / T_{n}$ is approximately between 0.1 and 0.5 . It must be noted that although it was not observed in this exercise, rebound failure is possible for structures with $\mathrm{T}_{\mathrm{d}} / \mathrm{T}_{\mathrm{n}}$ greater than 0.5 depending on the magnitude of the peak negative pressure. These observations are reflected in the dynamic response and impulsive response regions in the P-I curves shown in Figure 13.

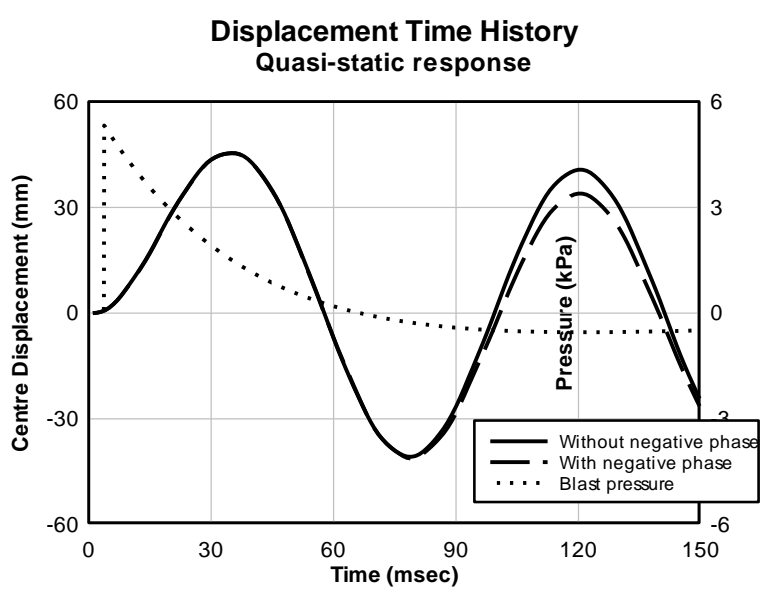

Figure 10. Comparison between FE Model Subjected to Quasi-static Loading Conditions with and without Negative Phase

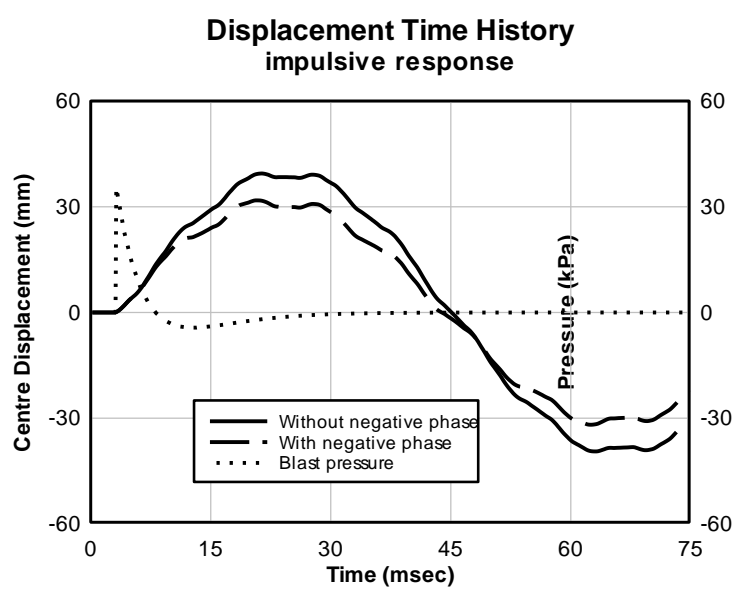

Figure 11. Comparison between FE Model Subjected to Impulsive Loading Conditions with and without Negative Phase

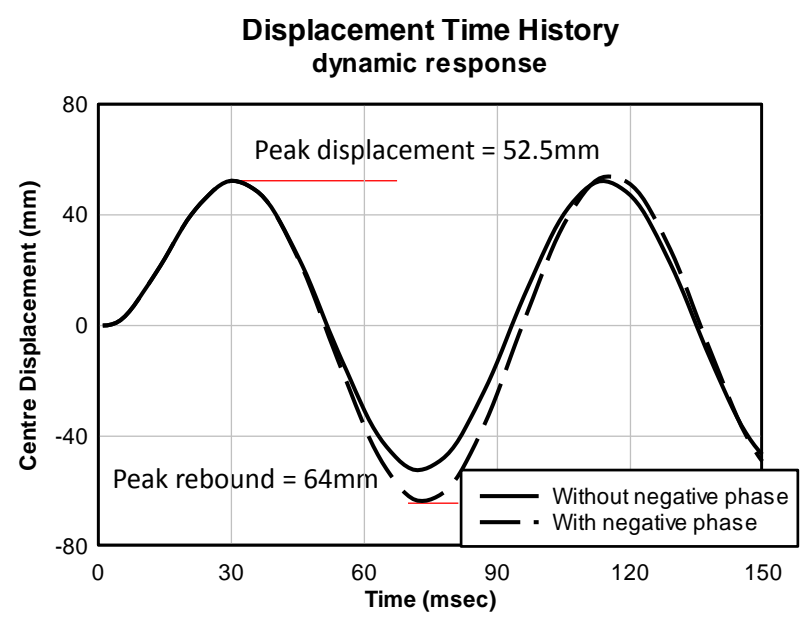

Figure 12. Comparison between FE Model Subjected to Dynamic Loading Conditions with and without Negative Phase 


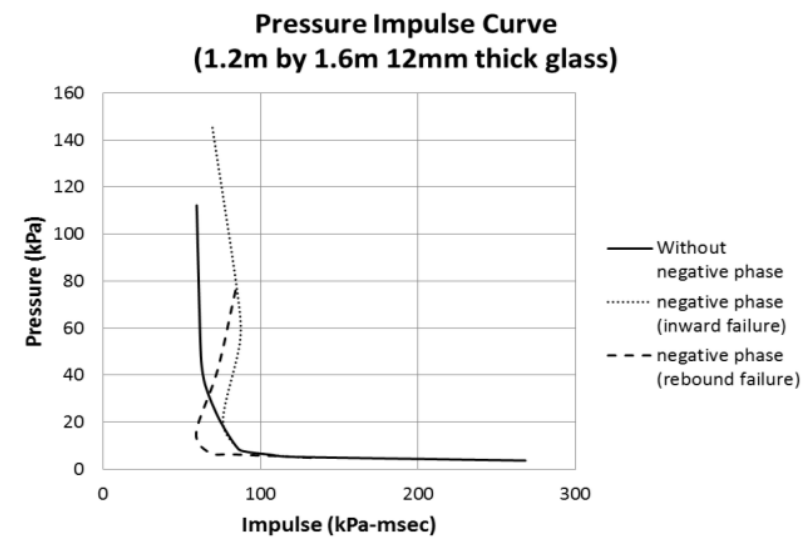

Figure 13. Influence of Negative Phase of Blast Pressure on Panel Performance

\section{Closing Remark}

A SDOF approach is generally used in the blast performance assessment of a façade component or other structural component due to its relatively low computational resources demand as compared to a detailed numerical modelling. Although the SDOF approach can be used with a reasonable degree of accuracy, the limitations of its basis assumption lead to loss of details in the idealisation process. This paper is an attempt to establish performance indices of a façade panel, and to identify the discrepancies between simplified approach and the detailed analysis.

The performance indices were developed in the form of P-I curves, which can be used to quickly indicate the 'fail' or 'no fail' state of the component once the blast pressure and specific impulse of an explosion is established. The analysis results indicated that factors such as higher mode shape of vibration and the negative phase of a blast pressure have an influence over the performance of the panel, which was reflected in the performance indices developed for the panel. It can be implied from the analysis results that neglecting the negative phase in the analysis may lead to un-conservative performance predictions in the dynamic response region and overly conservative performance predictions in the impulsive response region. The results of the analysis also highlight the importance of taking into account the negative phase of blast pressures, especially in analysis of materials or structural system with limited or no ductility.

\section{References}

1. Norville, H.S., Harvill, N., Conrath, E. J., Shariat, S. and Mallonee, S., Glass-Related Injuries in Oklahoma City Bombing, Journal of Performance of Constructed Facilities, 12(2),1999, pp. 50-56.
2. Jacob, L., ISO Safety Glass Impact Test Developments, Glass Processing Days, Proceedings of the $8^{\text {th }}$ International Glass Conference in Tampere, Tampere, Finland, 2003.

3. The American Society for Testings and Materials, Standard Test Method for Glazing and Glazing System Subject to Airblast Loading in Buildings, ASTM F1642, 2010.

4. Netherton, M.D. and Stewart, M.G., Blast Reliability Curves and Pressure-Impulse Curves: Complimentary Information for Decision Makers, Proceedings of the 2006 RNSA Security Technology Conference, Canberra, Australia, 2006.

5. Rose, T.A., Smith P.D. and Johnson, N.F., Assessment of Glazing Damage using Simple Pressure Impulse Relations in CFD Blast Calculation, $10^{\text {th }}$ International Symposium on Interaction of the Effects of Munitions with Structures. San Diego. USA, 2001.

6. Ma, G.W., Shi, H.J. and Shu, D.W., P-I Diagram Method for Combined Failure Modes of Rigidplastic Beams, International Journal of Impact Engineering, 34, 2007, pp. 1081-1094.

7. Shi, Y., Hao, H. and Li, Z.X., An Overview of Pressure-Impulse Diagram Derivation for Structure Components, Proceedings of the 2007 RNSA Security Technology Conference, Melbourne, Australia, 2007.

8. Smith, P.D. and Hetherington, J.G., Blast and Ballistic Loading on Structures, Oxford: Butterworth-Heinemann, 1994.

9. Hyde, D., CONWEP, Vicksburg, USA, US Army Corps of Engineers, 1993.

10. Rose, T., Air3D v9.0, UK, Cranfield University, 2005.

11. Kingery, C.N. and Bulmash, G., Airblast Parameters from TNT Spherical Air Burst and Hemispherical Surface Burst, Report ARBL-TR02555, U.S. Army BRL, Aberdeen Proving Ground, MD, 1984.

12. U.S. Department of the Army, Structures to Resist the Effect of Accidental Explosion, UFC 3340-02, 2008.

13. Ngo, T., Lumantarna, R. and Mendis, P., Protective Structures Research at The Univertsity of Melbourne, Australian Journal of Structural Engineering, 13(1), 2012, pp. 43-64.

14. Teich, M. and Gebbeken, N., The Influence of the Underpressure Phase on the Dynamic Response of Structures Subjected to Blast Loads, International Journal of Protective Structures, 2(1), 2010, pp. 219-233. 
15. Li, Q.M. and Meng, H., Pressure-Impulse Diagram for Blast Loads Based on Dimensional Analysis and Single-Degree-of-Freedom Model, Journal of Engineering Mechanics, 128(1), 2002, pp. 87-92.

16. Shi, Y., Hao, H. and Li, Z.X., Numerical Derivation of Pressure-impulse Diagrams for Prediction of RC Column Damage to Blast Loads, International Journal of Impact Engineering, 35, 2008, pp. 1213-1227.
17. Hallquist, J.O., LS-DYNA Keyword User's Manual, Livermore, Livermore Software Technology Corp., 2001.

18. Crawford, J.E. Analysis, Design, and Upgrade to Windows Subjected to Blast Loads, Short Course: An Introduction to Explosion Effects and Design for Blast, Melbourne, Australia, 2006. 